\title{
Toxicity characteristics of sewage treatment effluents and potential contribution of micropollutant residuals
}

\author{
Younghee $\mathrm{Kim}^{1 *}$ and Danvir Mark Farnazo ${ }^{2}$
}

\begin{abstract}
Background: A typical sewage treatment plant is designed for organic and nutrient removal from municipal sewage water and not targeted to eliminate micropollutants such as pesticides, pharmaceuticals, and nano-sized metals which become a big concern for sustainable human and ecological system and are mainly discharged from sewage treatment plant. Therefore, despite contaminant removal by wastewater treatment processes, there are still remaining environmental risks by untreated pollutants in STP (sewage treatment plant) effluents. This study performed aquatic toxicity tests of raw wastewater and treated effluents in two sewage treatment plants to evaluate toxicity reduction by wastewater treatment process and analyze concentration of contaminants to reveal potential toxic factors in STP effluents.

Methods: Water samples were collected from each treatment steps of two STPs, and acute and chronic toxicity tests were conducted following USEPA (United States Environmental Protection Agency) and OECD (Organization for Economic Cooperation and Development) guidelines. Endpoints were immobility for mortality and reproduction effect for estrogenicity.

Results: Acute $\mathrm{EC}_{50}$ S (median effective concentration) of influents for Seungki (SK) and Jungnang (JN) STPs are $54.13 \pm$ $32.64 \%$ and $30.38 \pm 24.96 \%$, respectively, and reduced to $96.49 \pm 7.84 \%$ and $100 \%$. Acute toxicity reduction was clearly correlated with SS (suspended solids) concentration because of filter feeding characteristics of test organisms. Chronic toxicity tests revealed that lethal effect was reduced and low concentration of influents showed higher number of neonates. However, toxicity reduction was not related to nutrient removal. Fecundity effect positively increased in treated wastewater compared to that in raw wastewater, and no significant differences were observed compared to the control group in JN final effluent implying potential effects of estrogenic compounds in the STP effluents.

Conclusions: Conventional wastewater treatment process reduced some organics and nutritional compounds from wastewater, and it results in toxicity reduction in lethal effect and positive reproductive effect but not showing correlation. Unknown estrogenic compounds could be a reason causing the increase of brood size. This study suggests that pharmaceutical residues and nanoparticles in STP effluents are one of the major micropollutants and underline as one of estrogenic effect factors.
\end{abstract}

Keywords: Toxicity reduction, Wastewater treatment, Micropollutants, Nanoparticle, Pharmaceuticals

\footnotetext{
* Correspondence: yhkim514@hoseo.edu

'Department of Convergence Technology, Graduate School of Venture, Hoseo University, 2497 Nambu Beltway, Seocho-gu, Seoul 06724, South Korea

Full list of author information is available at the end of the article
} 


\section{Background}

A typical sewage treatment plant (STP) is limited for organic and nutrient removal from municipal sewage water. Suspended solids (SS) are also one of the main targets to remove from wastewater. STP processes generally consist of primary settlement process for SS removal and biological treatment process for nutrient such as nitrogen and phosphorus removal. Biological treatment, which is called as the secondary treatment process, includes aerobic, anaerobic, and anoxic processes. Thus, it is expected that other micropollutants such as pharmaceuticals, personal health care products, and detergents are retained at the effluent stream which are subsequently released to the aquatic environment (Fent et al. 2006).

Environmental levels of pharmaceuticals varied from ppbs to ppts according to its media and discharge patterns (Vieno et al. 2005; Loraine and Pettigrove 2006) and their usage pattern (Balakrishna et al. 2017). Carbamazepine, an antidepressant drug, is one of the most detectable pharmaceuticals because of its persistency in the environment even though metformin showed the highest concentration of $8100 \mathrm{ng} / \mathrm{L}$ (Kot-Wasik et al. 2016). Pharmaceutical residues in the aquatic environment have been a big concern in terms of its consistent discharge from sewage but it is also considered nontoxic because of relatively low environmental levels and nonsevere acute toxicity resulting in a low risk to humans and aquatic animals.

Nanoparticles are also one of the major micropollutants which should be issued for human health and water environment. Nanomaterials are defined as less than $100 \mathrm{~nm}$ of their size and are well known as they show different physicochemical characteristics according to size. Drastically increased usage in the industry resulted in more detection in the environment. Health effects on human and the ecosystem have been studied but some toxicologists doubt its ecological effect because of its size distribution in the environment. Titanium oxides and zinc oxide are one of highranked compounds among industrial nanomaterials in terms of annual usage in Korea (Kim et al. 2014), and relevant detections have been reported as they are used for mainly consumer products which finally flows into water environment though STP effluent (Gottschalk et al. 2013). Like pharmaceuticals, ENM (engineered nanomaterials) were measured in the level of ppbs and ppts.

The main objective of this study is to investigate toxicity reduction by performing WET (whole effluent toxicity) tests on raw wastewater, treatment process effluents, and final effluents of sewage treatment plants. In addition, factors which could influence toxic effect in the effluent were studied by contaminant and nutrient removal analysis and by literature reviews.

\section{Methods}

\section{Sample collection}

Grab samples were collected in 2-L Mediland disposable sampling bags once a week from SK STP (Seungki Sewage Treatment Plant) in Incheon and JN STP (Jungnang Water Reclamation Center) in Seoul, South Korea, at each wastewater treatment process stage (Fig. 1) from July 15 to November 24, 2009, and transported to the laboratory and stored at $4{ }^{\circ} \mathrm{C}$ (7 days at most). SK and JN STPs are one of the major STPs in Incheon and Seoul, which hire biological treatment process; one is MLE (Modified Ludzack-Ettinger) and the other $\mathrm{A}^{2} \mathrm{O}$ (Aerobic-Anaerobic-Oxidation). The daily loads for SK and JN STPs and the daily volumetric capacities are $320,000 \mathrm{~m}^{3} /$ day and $460,000 \mathrm{~m}^{3} /$ day (This is the capacity for $\mathrm{A}^{2} \mathrm{O}$ process line used in this study. The total capacity of JN STP is $1,590,000 \mathrm{~m}^{3} /$ day.), respectively.

\section{Test organisms and culturing conditions}

Daphnia magna cultures were held in 3-L beakers containing moderately hard water $(80-100 \mathrm{mg} / \mathrm{L}$ as $\mathrm{CaCO}_{3}$ ) prepared following the US EPA Guideline (USEPA 2002). Cultures were maintained in a growth chamber at $21 \pm 1{ }^{\circ} \mathrm{C}$ and 16-h light: 8-h dark photoperiod was employed. The media were renewed every 2 days, and the daphnids were fed daily with $5 \mathrm{ml}$ YCT (Yeast:Ceropyll:Tetramin ${ }^{\circ}$ ) and $3 \mathrm{ml}$ living Chlorella $\left(1 \times 10^{7}\right.$ cells $\left./ \mathrm{ml}\right)$. Water qualities of the culture media were maintained as follows: $\mathrm{pH}, 7.4 \sim 7.8$; hardness, $80 \sim 100 \mathrm{mg} / \mathrm{L}$ as $\mathrm{CaCO}_{3}$; and alkalinity, $57 \sim 64 \mathrm{mg} / \mathrm{L}$ as $\mathrm{CaCO}_{3}$.

\section{Acute and chronic toxicity tests}

Acute toxicity tests $(48 \mathrm{~h})$ were conducted using the grab samples with concentration range of $6.25,12.5,25$, 50 , and 100 vol\% in accordance with the recommended procedure outlined in US EPA WET test (USEPA 2002). The immobility of test organisms was measured for endpoint. Standard reference tests were performed twice a month using sodium chloride as the test chemical to compare sensitivity of the test organisms over time.

Chronic toxicity tests (21 days) were conducted using the same range of concentration as mentioned under OECD TG (test guideline) 211 (OECD 2008). Ten neonates for each concentration were randomly selected and placed individually in 40-ml test solution of ten replicates. The test solutions were renewed every other day, and daphnids were fed with $150 \mu \mathrm{l}$ YCT and $100 \mu \mathrm{l}$ live Chlorella algae daily. The endpoints observed include molting, mortality, brood size, and number of brood and sex ratio of offspring. All experiments were carried out in the growth chamber at $21 \pm 1{ }^{\circ} \mathrm{C}$ and a 16 -h light:8-h dark photoperiod. 


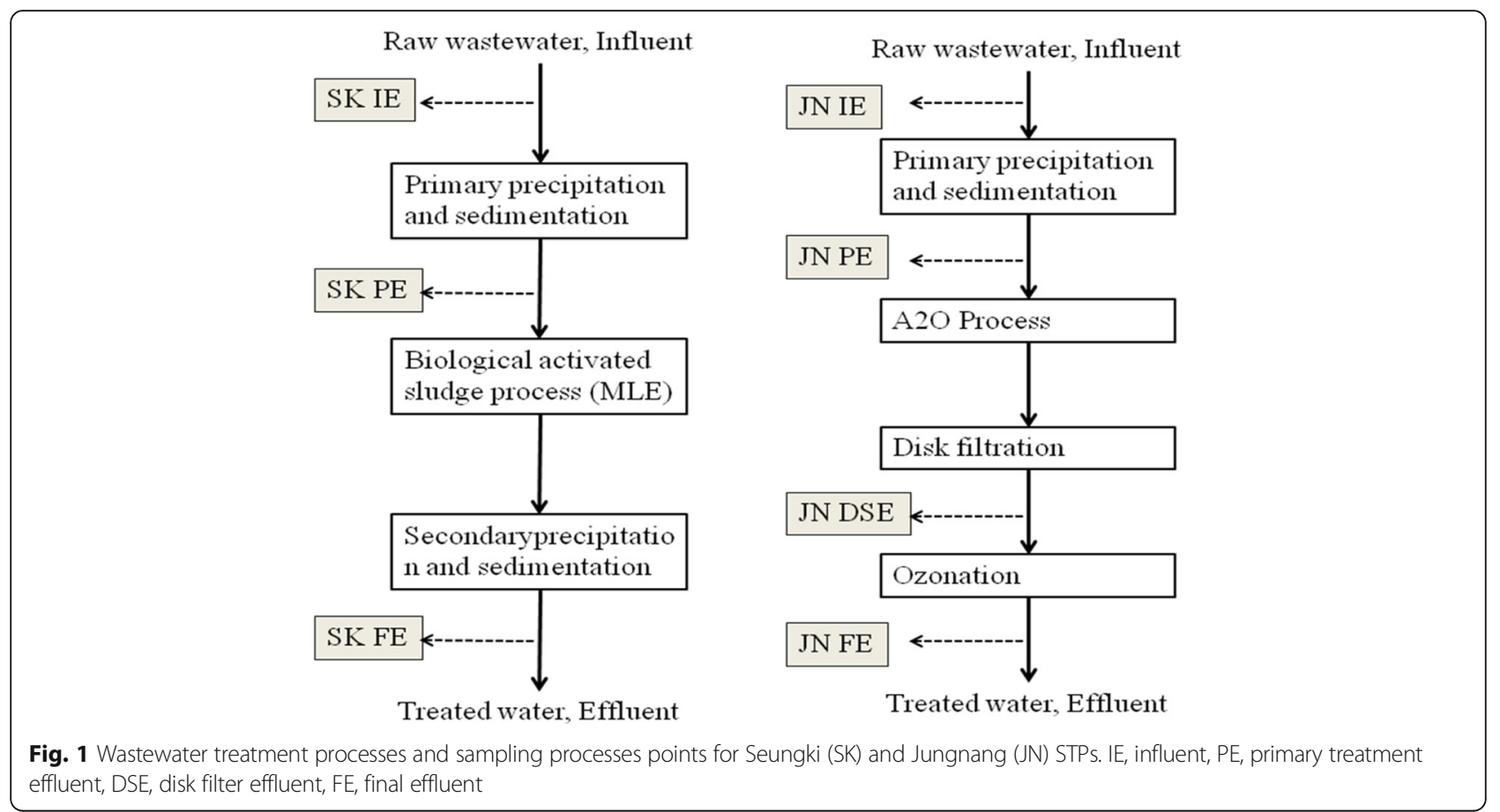

\section{Analytical methods and data analyses}

Measurement of the water quality parameters were done as follows: suspended solids (SS) - gravimetric methods, ammonia $\left(\mathrm{NH}_{4}-\mathrm{N}\right)$ and phosphate $\left(\mathrm{PO}_{4}-\mathrm{P}\right)-$ Branne + Luebbe Automatic Analyzer 3 with digital colorimeter, and $\mathrm{NO}_{3}-\mathrm{N}$ and $\mathrm{NO}_{2}-\mathrm{N}-$ Ion chromatography (Dionex ICS-100).

In statistical analysis, median effective concentratio$\mathrm{n}\left(\mathrm{EC}_{50}\right)$ for acute toxicity results and $25 \%$ inhibitory concentration $\left(\mathrm{IC}_{25}\right)$ for chronic reproductive results were calculated using probit analysis, SpearmanKarber and trimmed Spearman-Karber methods with ToxStat (Ver 3.5, West Inc., Cheyenne, WY, USA). Statistically significant differences in toxicity were determined using ANOVA test with SPSS (Ver. 10.0). Nominal concentrations were used throughout the course of the study.

\section{Results and discussion}

\section{Characteristics of wastewater}

The summary of water quality parameters and analysis results are presented in Table 1. Alkalinity and hardness levels for SK STP influent, primary treatment, and final effluents are higher than those of the moderately hard water (test media). However, the values of all the samples of JN STPs were within the range of the moderately hard water. Suspended solids (SS) contents of overall samples from SK STP were higher than those of JN STP except for influent samples. In JN STP, a significant reduction of suspended solids from biologically treated wastewater was the result of the secondary treatment employed using disk filtration. There are similarities in ammonia, nitrate, and nitrite levels in both STPs' raw wastewater,

Table 1 Water quality parameters obtained from the grab samples collected from Seungki and Jungnang STPS

\begin{tabular}{|c|c|c|c|c|c|c|c|}
\hline \multirow{2}{*}{$\begin{array}{l}\text { Water quality } \\
\text { parameter }\end{array}$} & \multicolumn{3}{|c|}{ Seungki Sewage Treatment Plant } & \multicolumn{4}{|c|}{ Jungnang Water Reclamation Center } \\
\hline & SK RW & SK PE & SK FE & JN RW & JN PE & JN DSE & JN FE \\
\hline $\mathrm{pH}$ & $8.1 \pm 0.1$ & $8.1 \pm 0.2$ & $7.9 \pm 0.7$ & $7.9 \pm 0.3$ & $7.9 \pm 0.2$ & $7.8 \pm 0.2$ & $7.8 \pm 0.1$ \\
\hline $\mathrm{DO}(\mathrm{mg} / \mathrm{L})$ & $6.1 \pm 2.2$ & $6.2 \pm 2.6$ & $8.2 \pm 1.0$ & $7.2 \pm 1.0$ & $7.5 \pm 1.6$ & $8.5 \pm 0.1$ & $8.7 \pm 0.1$ \\
\hline SS (mg/L) & $68.3 \pm 3.5$ & $54.7 \pm 6.4$ & $29.3 \pm 4.2$ & $161.7 \pm 26.2$ & $41.3 \pm 4.7$ & $2.8 \pm 0.4$ & $1.9 \pm 0.4$ \\
\hline Alkalinity $\left(\mathrm{mg} / \mathrm{L} \mathrm{CaCO}_{3}\right)$ & $154.1 \pm 27.2$ & $178.6 \pm 70.4$ & $99.4 \pm 16.3$ & $118.1 \pm 1.8$ & $126.4 \pm 3.0$ & $57.5 \pm 9.4$ & $59.1 \pm 6.2$ \\
\hline Hardness (mg/L $\left.\mathrm{CaCO}_{3}\right)$ & $201.7 \pm 20.2$ & $226.7 \pm 25.2$ & $170 \pm 20$ & $116.7 \pm 28.9$ & $126.7 \pm 15.3$ & $106.7 \pm 5.8$ & $105 \pm 5$ \\
\hline $\mathrm{NH}_{4}-\mathrm{N}(\mathrm{mg} / \mathrm{L})$ & $26.0 \pm 1.4$ & $21.7 \pm 0.2$ & $9.2 \pm 0.2$ & $21.7 \pm 0.3$ & $21.0 \pm 0.2$ & $1.7 \pm 0.0$ & $1.2 \pm 0.8$ \\
\hline $\mathrm{NO}_{3}-\mathrm{N}(\mathrm{mg} / \mathrm{L})$ & $16.1 \pm 2.1$ & $12.7 \pm 1.1$ & $8.6 \pm 1.8$ & $14.1 \pm 1.0$ & $13.8 \pm 1.7$ & $9.4 \pm 1.4$ & $6.4 \pm 1.6$ \\
\hline $\mathrm{NO}_{2}-\mathrm{N}(\mathrm{mg} / \mathrm{L})$ & $2.5 \pm 0.0$ & $1.9 \pm 0.8$ & $1.8 \pm 0.6$ & $3.2 \pm 0.4$ & $2.7 \pm 0.7$ & $1.7 \pm 0.1$ & $1.1 \pm 0.1$ \\
\hline $\mathrm{PO}_{4}-\mathrm{P}(\mathrm{mg} / \mathrm{L})$ & $3.9 \pm 0.0$ & $2.8 \pm 0.1$ & $0.9 \pm 0.0$ & $3.3 \pm 0.0$ & $1.9 \pm 0.0$ & $1.4 \pm 0.1$ & $0.60 \pm 0.0$ \\
\hline
\end{tabular}


primary treatment effluents, and final effluents. Phosphate concentration of raw wastewater is approximately doubly higher in SK STP than in JN STP but reduced to a similar level in final effluents both.

\section{Acute toxicity test results}

Results of the 48-h acute toxicity tests using Daphnia magna for the raw wastewater, treatment process effluents, and final effluents collected from SK and JN STPs generally indicate that the effective concentrations $\left(\mathrm{EC}_{50} \mathrm{~s}\right)$ increase with respect to the sequence of treatment (Fig. 2). There were no significant differences $(p>$ 0.05 ) between the raw wastewater samples and primary treatment effluents for both SK and JN STPs. However, $\mathrm{EC}_{50} \mathrm{~S}$ of the samples after the secondary treatment were significantly increased to $>100 \%$ indicating total acute lethal toxicity reduction of sewage wastewaters.

The data also revealed that the $\mathrm{A}^{2} \mathrm{O}$ process employed in JN STP could reduce daphnia acute toxicity with consistent results as indicated by narrower range of $\mathrm{EC}_{50}$ values. $\mathrm{EC}_{50} \mathrm{~S}$ of raw water samples varied regarding sampling time and toxicity reduction by the process is also varied (Fig. 3). For SK STP, the overall toxicity of the effluents was low during the summer and high during the winter implying decreased removal efficiency at low temperature. Specifically, the $E_{50} \mathrm{~s}$ of the raw wastewater and primary effluent varied dramatically with the seasons. This may be also brought about by the amount of rainfall received by the sewage intake system during the summer season, since heavy rains occur during summer, but fewer in winter (Ra et al. 2008).

It is generally assumed that the dissolved fraction of a toxic substance in surface water is mainly responsible for the toxicity to aquatic organisms. However, toxic compounds are often adsorbed or chemically bound to suspended particles in the water column, depending on the physico-chemical conditions. Daphnia magna are filter-feeding organisms, and contaminated particles might end up in the gastrointestinal tract and exert toxic effects (Weltens et al. 2000). In this study, an average $19.6 \%$ suspended solids (SS) reduction was observed in SK PE while a more effective decline was measured in JN PE with $74.44 \%$ average SS reduction. Although a secondary precipitation and sedimentation tank was employed after biological treatment in SK STP, final effluent SS were still moderately high with an average of $29.33 \mathrm{mg} / \mathrm{L}$. In contrast, disk filtration treatment employed in JN STP proved to be effective in decreasing the $\mathrm{SS}$ of the wastewater to $2.83 \pm 0.35 \mathrm{mg} / \mathrm{L}$.

\section{Chronic toxicity tests}

Raw wastewater and primary treatment effluents of $\mathrm{JN}$ STP exhibited mortality at low effective concentrations $\left(\mathrm{EC}_{50}\right)$ of $8.94 \pm 0.50 \%$ and $18.19 \pm 0.77 \%$, respectively. On the other hand, SK STP raw wastewater and primary treatment effluent $\mathrm{EC}_{50} \mathrm{~S}$ were identical to each other with values at $18.75 \%$. From the acute toxicity results, it was surmised that suspended solids in the water column may have highly contributed to the mortality of the Daphnia magna. Chronic exposure to suspended solids alone has been reported to induce detrimental and stimulate sublethal effects to daphnids as in their fecundity, growth, and juvenile survival at concentrations of 50 and $100 \mu \mathrm{g} / \mathrm{L}$ (Kirk 1992; Kirk and Gilbert 1990; Arruda et al. 1983; McCabe and O'Brien 1983). The result supports the previous study with the significant difference $(p<0.05)$ of the $\mathrm{EC}_{50} \mathrm{~s}$ of the SK and JN STPs' raw wastewater at $\mathrm{SS}$ values of $68.3 \pm 3.5 \mathrm{mg} / \mathrm{L}$ and

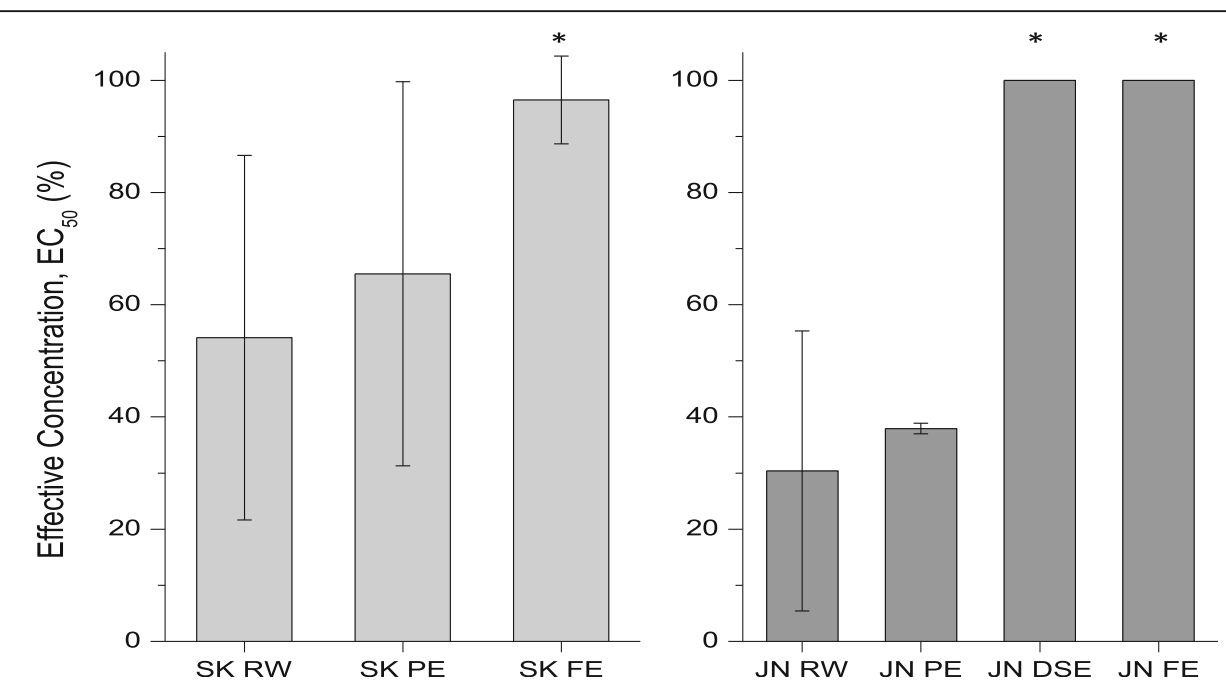

Fig. 2 Acute $48 \mathrm{~h}$ effective concentrations $\left(E_{50} \mathrm{~S}\right)$ of wastewater effluents from SK and JN STPs. Asterisks indicate significant difference with respect to raw wastewater samples 


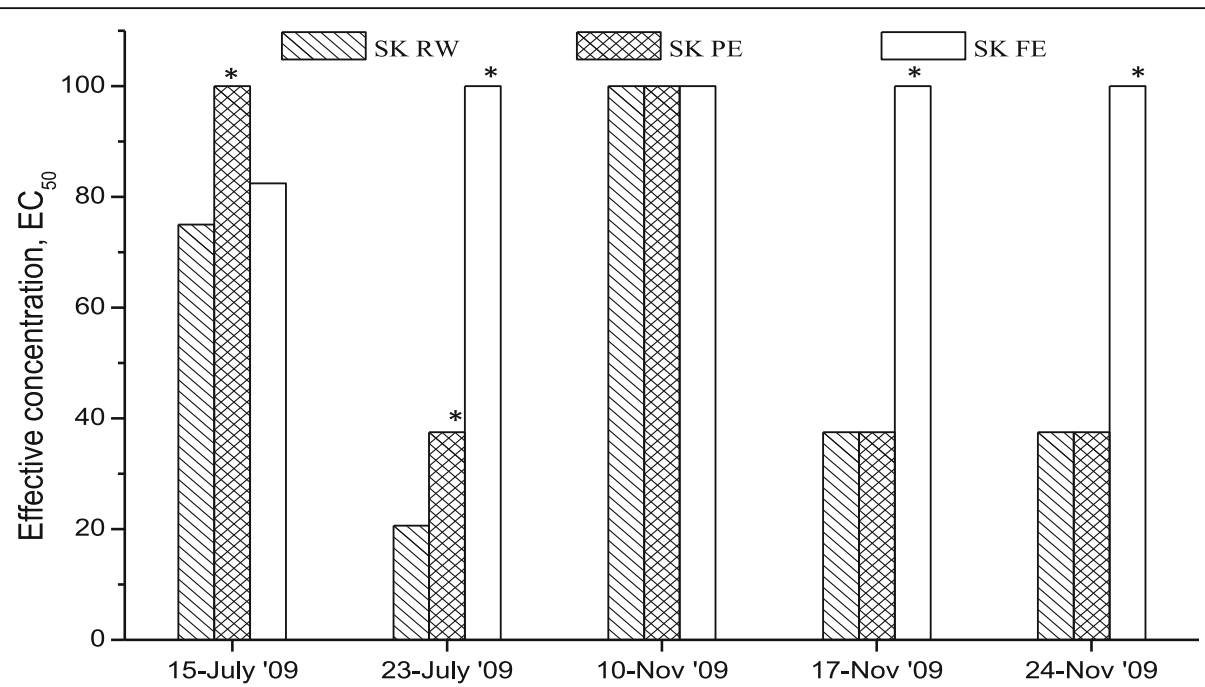

Fig. 3 Seasonal variations of the $\mathrm{EC}_{50}$ S of SK STP effluents. Asterisks indicate significant difference with respect to raw wastewater samples

$161.7 \pm 26.2 \mathrm{mg} / \mathrm{L}$, respectively. Significant reduction of the toxicity was noted with JN STP effluent after the primary treatment with $\mathrm{EC}_{50}$ improvement from $8.94 \pm$ $0.50 \%$ to $18.19 \pm 0.77 \%$. Additionally, disk filtration effluent of JN STP did not exert mortality to the daphnids (data not shown). In contrast, no improvement on the $\mathrm{EC}_{50}$ was observed in SK STP effluent because suspended solids content in the effluent remained relatively high at $54.7 \pm 6.4 \mathrm{mg} / \mathrm{L}$.

Besides mortality, average lifespan reflects the overall health and fitness of the test organisms during the 21day chronic exposure. Effluents from JN STP exhibited substantially truncated average daphnid lifespan, particularly those tested in raw wastewater at 8.34 days and primary treatment effluent at 11.14 days. Conversely, disk filtration and ozonation effluents influenced protracted average lifespan on the test organisms with values 20.80 and 20.78 days, respectively.

An extension of at least 1 day to the total days to gravidity of Daphnia magna prompts delay in the first day reproduction and may serve as an indication of the ensuing effect of exposure to suspended particles on their population (Fig. 4). SK STP effluents exhibited the described phenomenon strongly with first day of brooding at 9.0, 8.20 , and 8.60 for raw wastewater, primary treatment effluent, and final effluent. JN STP effluents reflected the opposite trend showing that time of the first brood recorded were 7.0, 7.50, 7.30, and 7.90 days. Previous studies reported that the duration of exposure to suspended solids played a more important role than suspended solids concentration in the delay of the number of days to gravidity of Daphnia magna (Robinson et al., 2009). However, data in this study support that concentration of SS could be more influential. Also significant correlation of nutrient removal by treatment process and toxicity reduction was not observed.
Figure 5 illustrates the fecundities of the effluent samples from SK STP and JN STP. The production of offspring per female for SK STP follows an inverted U-shaped trend and SK PE showed more clearly. On the other hand, JN STP did not follow th pattern implying less impact of SS and nutrient concentration on fecundity. In the water column of contaminated water, many pollutants adsorb to the suspended solids such as sediments, clay particles, and natural organic materials (Rodgers et al. 1987). Although many physicochemical parameters are involved, the adsorption behavior for organics, for example, endocrine disruptor chemicals (EDCs), pharmaceuticals and personal care products (PPCPs), pesticides, and heavy metals, can be predicted roughly from the compound's log $\mathrm{K}_{\mathrm{ow}}$ or oil/water partitioning coefficient (Admiraal et al. 1998). Allison and Allison (2005) summarized the partitioning coefficients of a myriad of heavy metals found in suspended matter. Works by Kim et al. (2007) enlisted the partitioning coefficients of some pharmaceuticals and disclosed the potential risks they impose to the receiving body of waters and its aquatic ecology. Several studies have shown removal of pesticides and pharmaceuticals from sewage effluent (Ternes et al. 2003; Ikehata et al. 2006; Ikehata et al. 2008; Okuda et al. 2008; Svenson et al. 2003; Andersen et al. 2003; Braga et al. 2005) but organic micropollutants pass through the STPs and enter the aquatic environment (Fent et al. 2006; Kummerer 2009). Especially, estrogenic compounds hardly removed by wastewater treatment processes (Andersen et al. 2003) and STP effluent denoted estrogenic effect (Nakada et al. 2004).

As the scope of this study did not include toxicity identification evaluation, we can only attribute the sublethal effects of the sample effluents on the fecundity of the Daphnia magna on suspended materials and particle-bound organic chemicals such as EDCs, PPCPs, and pesticides. One possible effect of contaminated particles on particle-feeding 


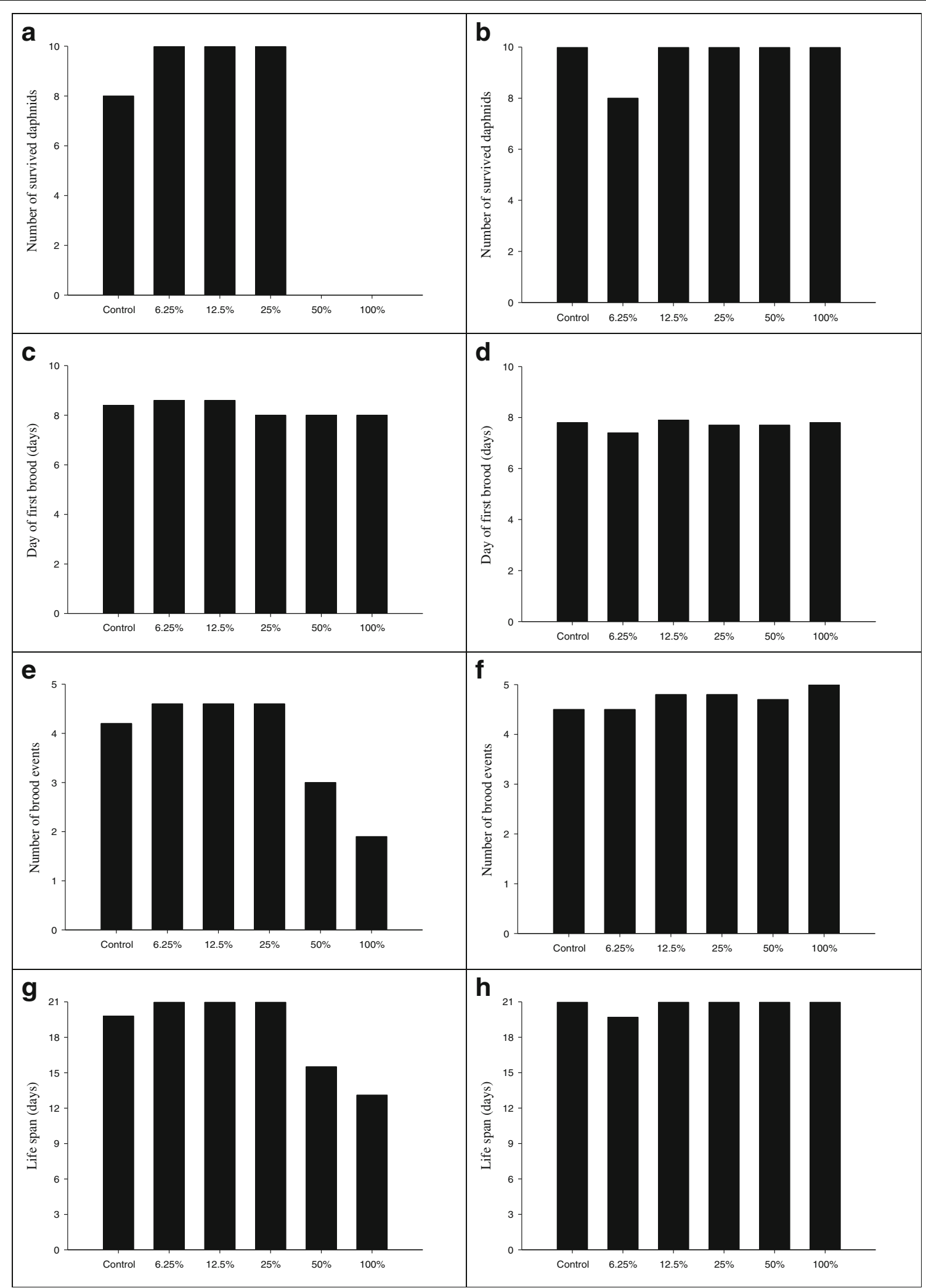

Fig. 4 Comparison of chronic toxicity test endpoints for SK and JN STPs final effluent. $\mathbf{a}, \mathbf{c}, \mathbf{e}, \mathbf{g}$ for SK STP efluent and $\mathbf{b}, \mathbf{d}, \mathbf{f}, \mathbf{h}$ for JN STP effluent 

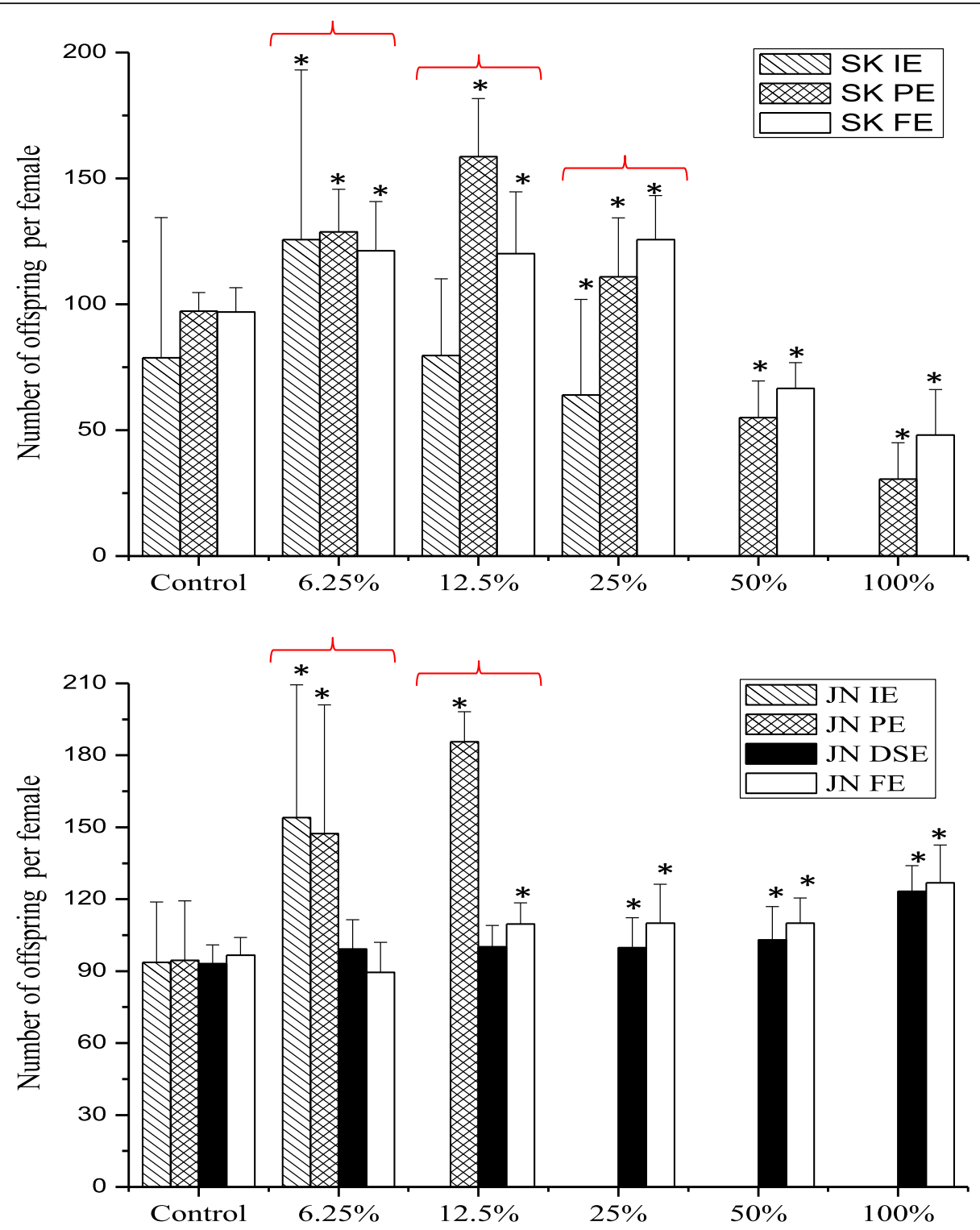

Fig. 5 Fecundities of Daphnia magna tested for SK and JN STP effluent samples. Asterisks indicate significant difference from control

organism like daphnids is a drastic reduction in food intake causing serious chronic effects on the population level. It has been shown many times that toxic products reduce food uptake in daphnids. Moreover, contaminated food particles affect food uptake even more than dissolve contaminants (Allen et al. 1995). The consequences to population growth of mortality during acute tests are commonly acknowledged, even though the relationship between survival and population growth is not a simple function (Caswell, 1989). Both field observations and laboratory studies have demonstrated that suspended materials can have deleterious effects on planktonic species including cladocerans (Bridges et al. 1996). For SK FE, JN DSE and JN FE where none or positive effects on daphnid fecundity were observed can be accredited to be result of ingestion of fine-grained sediment particles with nutritive values as shown in previous study (Dillon 1993; Ankley et al. 1994).

Sun et al. (2008) evaluated the estrogenic activities of the wastewater effluent samples and reported that since some estrogenic substances such as estradiol, bisphenol, and nonylphenol were discharged in conjugated forms, the microbial activity could deconjugate and reactivate them during the early steps of treatment. Hence, there are higher population densities for raw wastewater and primary treatment for both SK and JN STPs. Secondary treatment has been considered as one of the most effective treatment of processes to reduce the estrogenic activity in wastewater (Kirk et al. 2000; Leush et al. 2006). However, still some estrogenic compounds such as estrone showed only $6.3 \%$ of removal efficiency and implied high ecological risk (Belhaj et 


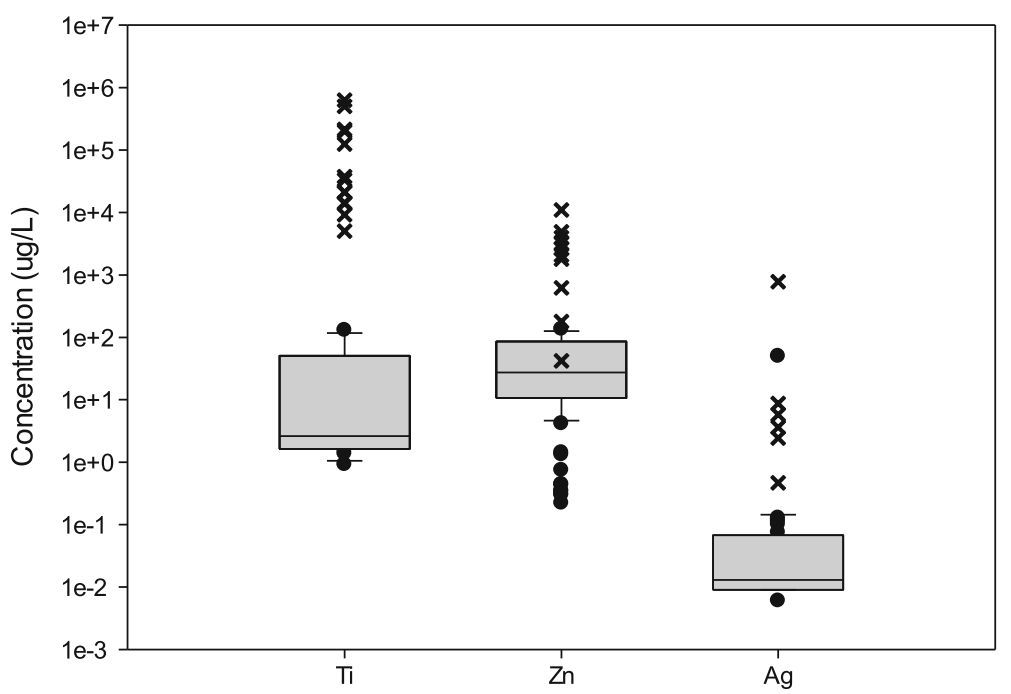

Fig. 6 Environmental level (•, other countries, X, South Korea) of nanoparticles and its toxicity level $\square$ ) on aquatic organisms Kim et al. (2010); Kim et al. (2014); Yang et al. (2013); Kiser et al. (2009); Westerhoff et al. (2011); Mitrano et al. (2012); Johnson et al. (2011a); Gottschalk et al. (2009); Johnson et al. (2011b); Khosravi et al. (2012); Hendren et al. (2013)

al. 2016). In addition, estrone in effluent showed higher level than in raw wastewater (Mailler et al. 2015; Belhaj et al. 2015), and pharmaceutical residues showed large variation of its removal efficiencies (Yang et al. 2017).

Another micropollutants, nanoparticles are also easily removed in STPs up to 95\% even though some are not totally removed (Tiede et al. 2011) and environmental concentration of nanoparticles are higher than toxicity levels so that it is hardly said nanoparticles are responsible for effluent toxicity (Fig. 6). However, many studies reveal a negative effect of nanoparticles on animals, especially on reproductive organs and reported that females are more vulnerable according to nanoparticle characteristics, exposure routes, and test animals (Brohi et al. 2017). It implicates that the potential role of nanoparticles on reproductive effect should not be neglected and further toxicity evaluation at low concentration is needed.

\section{Conclusions}

In this study, acute and chronic toxicity tests were successfully employed for the evaluation of the reduction of toxicity of sewage water effluents for two sewage treatment plants in SK STP, Incheon and JN STP, Seoul, Korea. Acute and chronic lethal effect decreased depending on SS removal by wastewater treatment process. As estrogenid effect, fecundity of daphnids was significantly increased in the influent and primary effluents implying presence/attribution of endocrine disrupting chemicals which controls reproduction and embryogenesis in mysid crustaceans. Pharmaceutical residues and nanoparticles in the effluents could be suggested as possible sources for estrogenic effect referring to previous study.
However to identify and clarify the potential role of micropollutants on reproduction, further toxicity evaluation is needed.

\section{Acknowledgements}

This research was supported by the Academic research fund of Hoseo university in 2014(Project number: 2014-0442).

\section{Funding}

This study was funded by the Hoseo University research program (2014-0442).

Availability of data and materials

Not available.

\section{Authors' contributions}

DMF conducted toxicity tests and statistical analysis. YK designed the study, drafted and revised manuscript. Both authors read and approved the final manuscript.

Ethics approval and consent to participate Not Applicable.

Consent for publication

Not Applicable.

\section{Competing interests}

The authors declare that they have no competing interests.

\section{Publisher's Note}

Springer Nature remains neutral with regard to jurisdictional claims in published maps and institutional affiliations.

\section{Author details}

'Department of Convergence Technology, Graduate School of Venture, Hoseo University, 2497 Nambu Beltway, Seocho-gu, Seoul 06724, South Korea. ${ }^{2}$ Energy and Environment Fusion Technology Center (E2FTC), Department of Environmental Technology and Biotechnology, Myongji University, San 38-2 Namdong, Cheoin-gu, Yongin City, Gyeonggi 17058, South Korea. 
Received: 29 September 2017 Accepted: 10 November 2017 Published online: 25 November 2017

\section{References}

Admiraal, W., Tubbing, G. M. J., \& Breebaart, L. (1998). Effects of phytoplankton on metal partitioning in the lower River Rhine. Water Resource., 29, 941-946.

Allen, Y., Calow, P., \& Baird, D. (1995). A mechanistic model of contaminant induced feeding in Daphnia magna. Environmental Toxicology and Chemistry, 14(9), 1625-1630.

Allison, J., \& Allison, T. (2005). Partition coefficients for metals in surface water, soil, and waste. Washington D.C: US Environmental Protection Agency, Office of Research and Development.

Andersen, H., Siegrist, H., Halling-Sørensen, B., \& Ternes, T. A. (2003). Fate of estrogens in a municipal sewage treatment plant. Environmental Science and Technology, 37, 4021-4026.

Ankley, G., Benoit, D. A., Balogh, J. C., Reynoldson, T. B., Day, K. E., \& Hoke, R. A. (1994). Evaluation of potential confounding factors in sediment toxicity tests with three freshwater benthic invertebrates. Environmental Toxicology and Chemistry, 13(4), 627-635.

Arruda, J. A., Marzolf, G. R., \& Faulk, R. T. (1983). The role of suspended sediments in the nutrition of zooplankton in turbid reservoirs. Ecology, 64, 1225-1235.

Balakrishna, K., Rath, A., Praveenkumarreddy, Y., Guruge, K. S., \& Subedi, B. (2017). A review of the occurrence of pharmaceuticals and personal care products in Indian water bodies. Ecotoxicology and Environmental Safety, 137, 113-120.

Belhaj, D., Baccar, R., Jaabiri, I., Bouzid, J., \& Zhou, J. L. (2015). Fate of selected estrogenic hormones in an urban sewage treatment plant in Tunisia (North Africa). Science of the Total Environment, 505, 154-160.

Belhaj, D., Athmouni, K., Jerbi, B., Kallel, M., Ayadi, H., \& Zhou, J. L. (2016). Estrogenic compounds in Tunisian urban sewage treatment plant: occurrence, removal and ecotoxicological impact of sewage discharge and sludge disposal. Ecotoxicology, 10, 1849-1857.

Braga, O., Smythe, G. A., Schafer, A. I., \& Feitz, A. J. (2005). Fate of steroid estrogens in Australian inland and coastal wastewater treatment plants. Environmental Science and Technology, 39, 3351-3359.

Bridges, T. S., Wright, R. B., Gray, B. R., Gibson, A. B., \& Dillon, T. M. (1996). Chronic toxicity of Great Lakes sediments to Daphnia magna: Elutriate effects on survival, reproduction, and population growth. Ecotoxicology, 5, 83-102.

Brohi, R. D., Wang, L., Talpur, H. S., Wu, D., Khan, F. A., Bhattarai, D., Rehman, Z.-U., Farmanullah, F., \& Huo, L.-J. (2017). Toxicity of Nanoparticles on the Reproductive System in Animal Models: A Review. Frontiers in Pharmacology, 8,606

Caswell, H. (1989). Matrix population models: construction, analysis and interpretation. Sunderland: Sinauer Associates, Inc

Dillon, T. M. (1993). Developing chronic sublethal sediment bioassays: A challenge to the scientific community. In J. W. Gorsuch, F. J. Dwyer, C. G. Ingersoll, \& T. W. La Point (Eds.), Environmental toxicological and risk assessment (Vol. 2, pp. 623-639). Philidephia: ASTM Publication. ISBN: 0-80311485-0.

Fent, K., Weston, A. A., \& Caminada, D. (2006). Ecotoxicology of human pharmaceuticals. Aquatic Toxicology, 76, 122-159.

Gottschalk, F., Sonderer, T., Scholz, R. W., \& Nowack, B. (2009). Modeled environmental concentrations of engineered nanomaterials ( $\mathrm{TiO}(2), \mathrm{ZnO}, \mathrm{Ag}$, CNT, Fullerenes) for different regions. Environmental Science and Technology, 43, 9216-9222.

Gottschalk, F., Sun, T. Y., \& Nowack, B. (2013). Environmental concentrations of engineered nanomaterials: Review of modeling and analytical studies. Environmental Pollution, 181, 287-300.

Hendren, C. O., Badireddy, A. R., Casman, E., \& Wiesner, M. R. (2013). Modeling nanomaterial fate in wastewater treatment: Monte Carlo simulation of silver nanoparticles (nano-Ag). Science of the Total Environment, 449, 418-425.

Ikehata, K., El-Din, M. G., \& Snyder, S. A. (2008). Ozonation and advanced oxidation treatment of emerging organic pollutants in water and wastewater. Ozone Science and Engineering, 30, 21-26.

Ikehata, K., Naghashkar, N. J., \& El-Din, M. G. (2006). Degradation of aqueous pharmaceuticals by ozonation and advanced oxidation processes: A review. Ozone Science and Engineering, 28, 353-414

Khosravi, K., Ehsanul Hoque, M., Dimock, B., Hintelmann, H., \& Metcalfe, C. D. (2012). A novel approach for determining total titanium from titanium dioxide nanoparticles suspended in water and biosolids by digestion with ammonium persulfate. Analytical Chimica Acta., 713, 86-91.
Kot-Wasik, A., Jakimska, A., \& Śliwka-Kaszyńska, M. (2016). Occurrence and seasonal variations of 25 pharmaceutical residues in wastewater and drinking water treatment plants. Environmental Monitoring Assessment, 188, 661.

Johnson, A., Cisowska, I., Jurgens, M., Keller, V., Lawlor, A., \& Williams, R. (2011a). Exposure Assessment for Engineered Silver Nanoparticles throughout the Rivers of England and Wales (CBO433). UK: Centre for Ecology and Hydrology.

Johnson, A. C., Bowes, M. J., Crossley, A., Jarvie, H. P., Jurkschat, K., Jürgens, M. D., Lawlor, A. J., Park, B., Rowland, P., Spurgeon, D., Svendsen, E., Thompson, I. P., Barnes, R. J., Williams, R. J., \& Xu, N. (2011b). An assessment of the fate, behaviour and environmental risk associated with sunscreen $\mathrm{TiO} 2$ nanoparticles in UK field scenarios. Science of the Total Environment, 409, 2503-2510.

Kim, S. J., Lee, B. C., Lee, S. H., Yoon, J. H., Lee, J. A., Ryu, T. K., Cuong, D. N., Kim, K. T., Cho, J. G., Lee, J. W., Kim, J. E., Seo, G. B., Choi, M., Baek, Y. W., Kim, P. J., \& Kim, S. C. (2010). Study on hazardous properties of manufactured silver nanoparticles, National Institute of Environmental Research, NIER NO. 2010-491224.

Kim, Y., Choi, K., Jung, J., Park, S., Kim, P. J., \& Park, J. (2007). Aquatic toxicity of acetaminophen, carbamazepine, cimetidine, diltiazem, and six major sulfonamides, and their potential ecological risks in Korea. Environment International, 33, 370-375.

Kim, Y., Sin, H. H., Sung, H., Oh, S. Y., Jeong, U., Park, J., Bae, E., Jang, A., Lee, U. J., Lee, Y. G., Kim, K., Lee, Y. E., An, Y.-J., Kwak, J. I., Kim, S. W., Nam, S.-H., Cui, R., \& Chae, Y. (2014). Assessment of Environmental Exposure of Nanomaterials in Aqueous Phase, NIER-SP2014-233.

Kirk, K. L. (1992). Effects of suspended clay on daphnia body growth and fitness. Freshwater Biology, 28, 103-109.

Kirk, K. L., \& Gilbert, J. J. (1990). Suspended clay and the population dynamics of planktonic rotifers and cladocerans. Ecology, 71, 1741-1755.

Kirk, L. A., Tyler, C. R., Lye, C. M., \& Sumpter, J. P. (2002). Changes in estrogenic and androgenic activities at different stages of wastewater treatment works. Environmental Toxicology and Chemistry, 21, 972-979.

Kiser, M. A., Westerhof, P., Benn, T., Wang, Y., Pérez-Rivera, J., \& Hristovski, K. (2009). Titanium nanomaterial removal and release from wastewater treatment plants. Environmental Science and Technology, 43, 6757-6763.

Kummerer, K. (2009). The presence of pharmaceuticals in the environment due to human use - present knowledge and future. Journal of Environmental Manage, 90, 2354-2366.

Leush, F. D. L., Chapman, H. F., van der Heuvel, M. R., Tan, B. L. L., Gooneratne, S. R. S., \& Tremblay, L. A. (2006). Bioassay-derived androgenic and estrogenic activity in municipal sewage in Australia and New Zealand. Ecotoxicology and Environmental Safety, 65, 403-411.

Loraine, G. A., \& Pettigrove, M. E. (2006). Seasonal Variations in Concentrations of Pharmaceuticals and Personal Care Products in Drinking Water and Reclaimed Wastewater in Southern California. Environmental Science and Technology, 40, 687-695.

Mailler, R., Gasperi, J., Coquet, Y., Deshayes, S., Zedek, S., Cren-Olivé, C., Cartiser, D., Eudes, V., Bressy, A., Caupos, E., Moilleron, R., Chebbo, G., \& Rocher, V. (2015). Study of a large scale powdered activated carbon pilot: Removals of a wide range of emerging and priority micropollutants from wastewater treatment plant effluents. Water Research, 72, 315-330.

McCabe, G. D., \& O'Brien, W. J. (1983). The effects of suspended silt on feeding and reproduction of Daphnia pulex. American Midland Naturalist, 110, 324337.

Mitrano, D. M., Lesher, E. K., Bednar, A., Monserud, J., Higgins, C. P., \& Ranville, J. F. (2012). Detecting nanoparticulate silver using single-particle inductively coupled plasma-mass spectrometry. Environmental Toxicology and Chemistry, 31, 115-121.

Nakada, N., Nyunoya, H., Nakamura, M., Hara, A., Iguchi, T., \& Takada, H. (2004). Identification of estrogenic compounds in wastewater effluent. Environmental Toxicology and Chemistry, 23, 2807-2815.

OECD, 2008. OECD guideline for testing of chemical, Section 2: Effects on biotix systems. Test No. 211: Daphnia magna reproduction test. ISBN: 9789264070127.

Okuda, T., Kobayashi, Y., Nagao, R., Yamashita, N., Tanaka, S., Fuji, S., Konishi, S. Konishi, C., \& Houwa, I. (2008). Removal efficiency of 66 pharmaceuticals during wastewater treatment process in Japan. Water Science and Technology, 57, 65-71.

Ra, J. S., Lee, B. C., Chang, N. I., \& Kim, D. S. (2008). Comparative whole effluent toxicity assessment of wastewater treatment plant effluents using Daphnia magna. Bulletin of Environmental Contamination and Toxicology, 80, 196-200. 
Robinson, S. E., Capper, N. A., \& Klaine, S. J. (2009). The effects of continuous and pulsed exposures of suspended clay on the survival, growth, and reproduction of Daphnia magna. Environmental Toxicology and Chemistry, 29, 168-175.

Rodgers, J. H., Jr., Dickson, K. L., Saleh, F. Y., \& Staples, C. A. (1987). Bioavailability of sediment-bound chemicals to aquatic organisms; some theory, evidence and research methods. In K. L. Diskson, A. W. Maki, \& W. A. Brungs (Eds.), Fate and effects of sediment-bound chemicals in aquatic systems (pp. 245-266). N.Y. Pergammon.

Sun, Q., Deng, S., Huang, J., Shen, G., \& Yu, G. (2008). Contributors to estrogenic activity in wastewater from a large wastewater treatment plant in Beijing, China. Environmental Toxicology and Pharmacology, 25, 20-26.

Svenson, A., Allard, A., \& Ek, M. (2003). Removal of estrogenicity in Swedish municipal treatment plants. Water Research, 37, 4433-4443.

Ternes, T. A., Stüber, J., Herrmann, N., McDowell, D., Ried, A., Kampmann, M., \& Teiser, B. (2003). Ozonation: a tool for removal of phatmaceuticals, contrast media and musk fragrances from wastewater? Water Research, 37, 1976-1983.

Tiede, K., Westerhoff, P., Hansen, S. F., Fern, G. J., Hankin, S. M., Aitken, R. J., Chaudhry, Q., \& Boxall, A. (2011). Review of the Risks Posed to Drinking Water by Man-made Nanoparticles. Sand Hutton, York: Food and Environment Research Agency. YO41 1LZ.

USEPA. (2002). Methods for measuring the acute toxicity of effluents of receiving waters to freshwater and marine organisms (5th ed.). EPA-821-02-012.

Vieno, N. M., Tuhkanen, T., \& Kronberg, L. (2005). Seasonal Variation in the Occurrence of Pharmaceuticals in Effluents from a Sewage Treatment Plant and in the Recipient Water. Environmental Science and Technology, 39, 82208226.

Weltens, R., Goossens, R., \& van Puymbroeck, S. (2000). Ecotoxicology of contaminated suspended solids for the filter feeders (Daphnia magna). Archives of Environmental Contamination and Toxicology, 39, 315-323.

Westerhoff, P., Song, G., Hristovski, K., \& Kiser, M. A. (2011). Occurrence and removal of titanium at full scale wastewater treatment plants: implications for TiO(2) nanomaterials. Journal of Environmental Monitoring, 13, 1195-1203.

Yang, Y., Zhang, C., \& Hu, Z. (2013). Impact of metallic and metal oxide nanoparticles on wastewater treatment and anaerobic digestion. Environmental Science: processes impacts, 15, 39-48.

Yang, Y., Ok, Y. S., Kim, K.-H., Kwon, E. E., \& Tsang, Y. F. (2017). Occurrences and removal of pharmaceuticals and personal care products (PPCPS) in drinking water and water/sewage treatment plants: A review. Science of the Total Environment, 596-597, 303-320.

\section{Submit your next manuscript to BioMed Central and we will help you at every step:}

- We accept pre-submission inquiries

- Our selector tool helps you to find the most relevant journal

- We provide round the clock customer support

- Convenient online submission

- Thorough peer review

- Inclusion in PubMed and all major indexing services

- Maximum visibility for your research

Submit your manuscript at www.biomedcentral.com/submit

C Biomed Central 